\title{
Aetiology of secondary otalgia in Mosul Medical City
}

Ali A. Muttalib Mohammed ${ }^{a}$, Raghdan M. D. Alhamdani ${ }^{\mathrm{b}}$, Haitham A. Alnoori ${ }^{\mathrm{a}}$, Khalid D. Hamad $^{\mathrm{b}}$ From the ${ }^{a}$ Department of Surgery, College of Medicine, University of Mosul, ${ }^{b}$ Department of ENT, Aljamhory Teaching Hospital, Mosul, Iraq. Correspondence: Ali A. Muttalib Mohammed ${ }^{a}$. aamuttalib@yahoo.com.

(Ann Coll Med Mosul 2013; 39 (2): 123-127).

Received: $7^{\text {th }}$ Jan. 2013; Accepted: $18^{\text {th }}$ Jun. 2013.

\section{ABSTRACT}

Objectives: The aim of the present study is to evaluate the aetiology of secondary (referred) otalgia.

Patients and methods: A case series study of 79 patients clinically diagnosed as secondary otalgia, collected from the Outpatient Department of ENT at Al-Jamhory Teaching Hospital, Mosul/IRAQ, and private clinics, for the period from Jan. 2010 to Sept. 2011.

Results: The average age of the patients was 33.3 years with a range of 4-80 years. The peak age incidence was in the fourth decade of life. The study included 34 male patients (43.1\%) and 45 females $(56.9 \%)$ with a ratio of $1: 1.3$. Temporomandibular joint dysfunction was found to be the main cause of secondary otalgia (37.9\%). Pharyngitis (24\%), dental pain (17.7\%) and cervical spine pain $(7.6 \%)$ came next in that order.

Conclusion: Temporomandibular joint dysfunction, pharyngitis, dental problems and cervical nerve root pain were the commonest causes of secondary otalgia. Moreover, upper aerodigestive tract malignancies should be considered in differential diagnosis.

Keywords: Secondary otalgia, referred otalgia, referred ear pain.

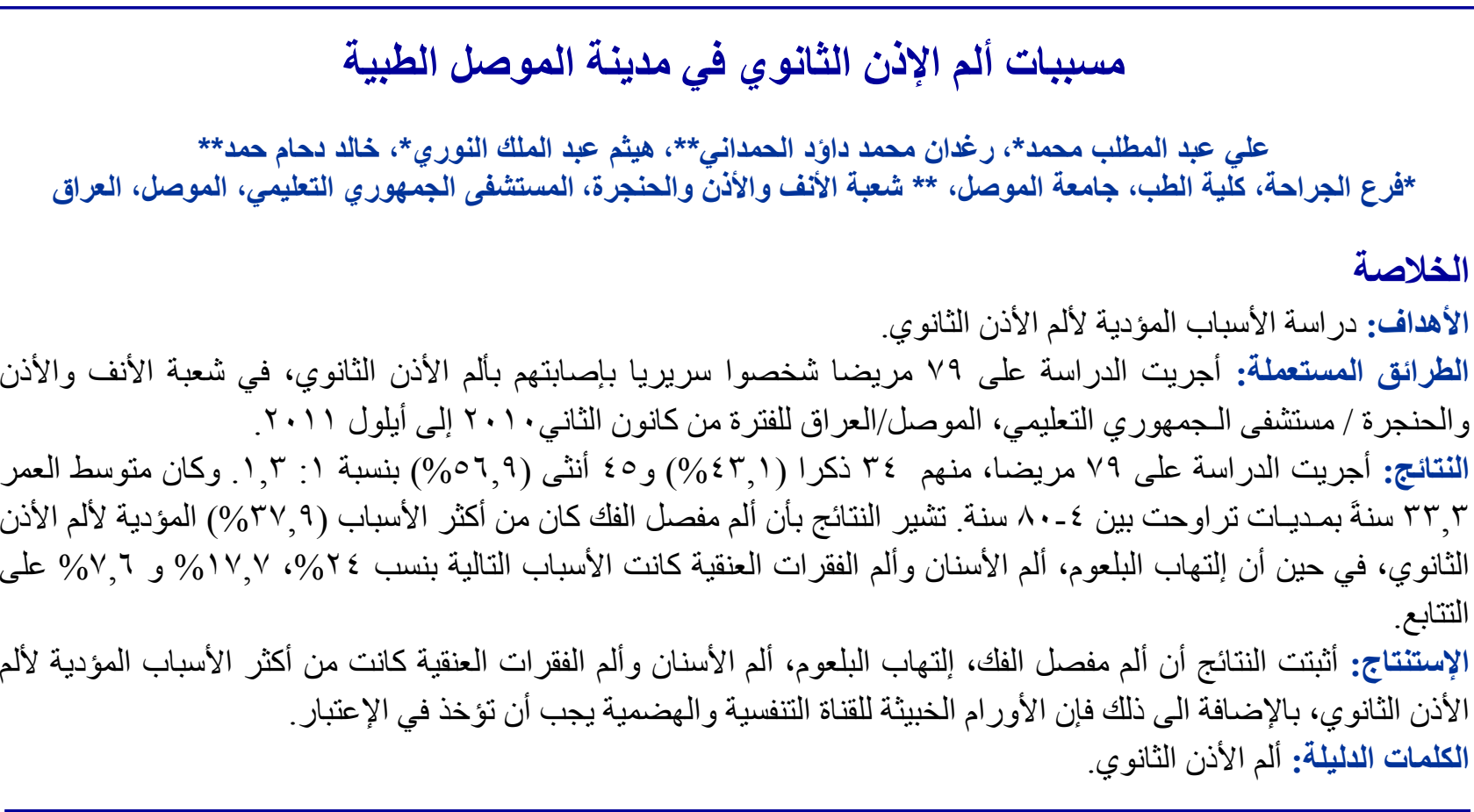

\section{INTRODUCTION}

A ccording to the Talmud (fifth century A.D.), the juice of a kidney was the recommended remedy for 'Otalgia'.'

Ear pain (otalgia) can be divided into 2 main types: primary and secondary. Primary ear pain is an entity whereby the origin of pain comes from the ear itself. In close to $50 \%$ of cases, however, the source of pain does not reside within the ear but rather originates from sources distant from the ear-so called "referred otalgia". ${ }^{2}$ Referred otalgia 
can be likened to an "alarm bell" signaling a head and neck ailment often of benign nature, yet, it may be the earliest warning of a veiled malignancy. ${ }^{1}$

The sensory innervations of the ear is served by auriculotemporal branch of the fifth cranial nerve, the first and second cervical nerves, the Jacobson branch of the glossopharyngeal nerve, the Arnold branch of the vagus nerve and the Ramsey Hunt branch of the facial nerve. Not surprisingly, noxious stimulation of any branch of cranial nerves $\mathrm{V}, \mathrm{VII}, \mathrm{IX}, \mathrm{X}$ and cervical nerves 1,2 and 3 may be interpreted as otalgia. ${ }^{3}$

If pathologic problems in the area supplied by these nerves have been ruled out, the neuralgia should be considered in the differential diagnosis. Psychogenic factors must be identified and treated before any type of surgical therapy is recommended. The complexity of this field may sometimes require the caring physician to call for consultations from colleagues in the fields of oral surgery, orthopaedics, neurology, or neurosurgery. ${ }^{4}$

Our study was designed to evaluate the causes of referred (secondary) otalgia.

\section{PATIENTS AND METHODS}

This case series study is concerned with 79 patients presented with secondary (referred) otalgia. The cases were collected from the Outpatient Department of ENT at Al-Jamhory Teaching Hospital, Mosul/IRAQ and the private clinics of the authors for the period from Jan. 2010 to Sept. 2011. Detailed history was taken and full ENT examination was performed including rigid and fibro-optic endoscopy of the nasal cavity, postnasal space, larynx and hypopharynx. All patients were proved to have secondary otalgia after excluding any primary cause.

Investigations like $\mathrm{X}$-ray of temporomandibular joint, orthopantomogram (OPG), X-ray of cervical veretebrae, CT scan and MRI were done accordingly. Dentist and rheumatologist consultation was obtained accordingly to confirm diagnosis of temporomandibular joint dysfunction, dental pain and cervical spondylosis.

The parameters analyzed included age and sex of patients and site, duration, frequency and severity of otalgia. The severity of aural pain was assessed by patients using visual score. Finally, the most likely diagnosis of secondary otalgia was documented.

\section{RESULTS}

The study included 34 male patients $(43.1 \%)$ and 45 females $(56.9 \%)$ with a ratio of $1: 1.3$ (Figure 1 ). The mean age of our patients was 33.3 years with a range of 4-80 years. The frequency of secondary otalgia increased with age where the peak age of presentation was in the fourth decade of life and thereafter decreased in old age groups (Figure 2).

Sixty two patients $(78.5 \%)$ complained from otalgia inside the ear, whereas 12 patients $(15.2 \%)$ stated that they felt otalgia around the ear. The remaining 5 patients (6.3\%) complained from otalgia in and around the ear.

Evaluation of severity of pain was done according to pain visual analog scale (Figure 3). Seven patients $(8.8 \%)$ referred that their pain was very severe (5), whereas 26 patients (33\%) documented that their pain was severe (4). Moderate (3) aural pain was felt by 29 (36.6\%) patients. Fifteen (19\%) and $2(2.6 \%)$ patients stated that referred otalgia was mild (2) and very mild (1) respectively.

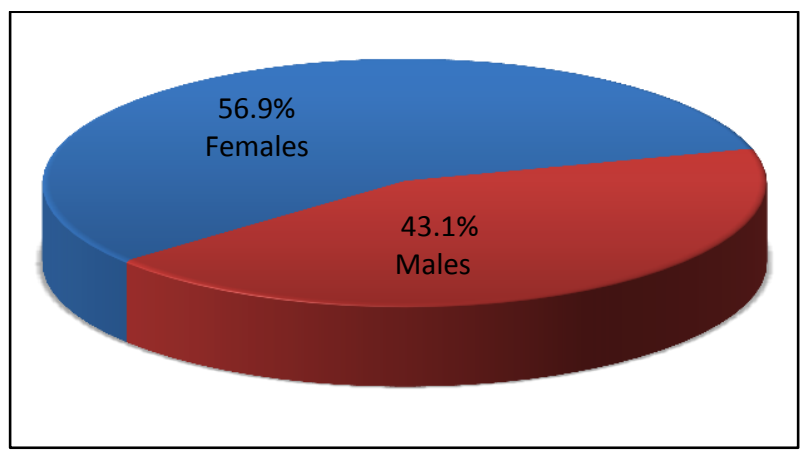

Figure 1. Sex distribution of the patients among the sample of study.

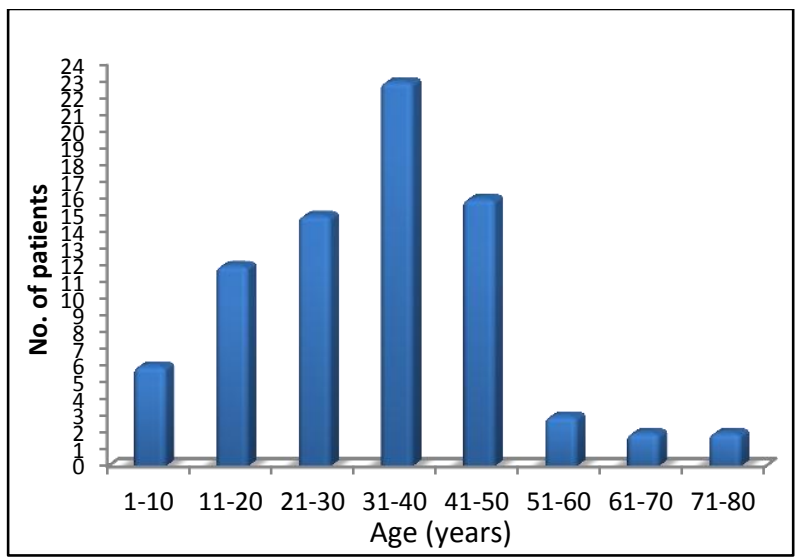

Figure 2. Age distribution of the patients among the sample of study. 
Figure 3. Pain visual analog scale. Reprinted from reference 5 .

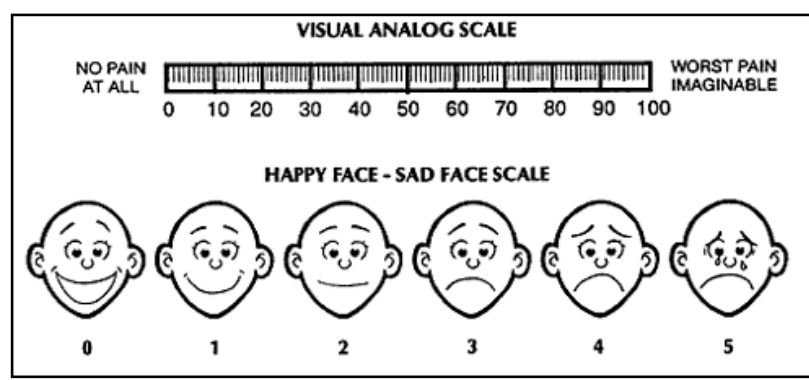

Temporomandibular joint dysfunction was found to be the main cause of secondary otalgia in $37.9 \%$ of patients with a mean age at presentation of 34.7 years. Pharyngitis $(24 \%)$, dental pain $(17.7 \%)$ and cervical spondylosis or myalgia $(7.6 \%)$ were the other causes of secondary otalgia (Table 1). It can be concluded from (Table 1) that females dominate in almost all diseases apart from pharyngitis. Moreover, upper aerodigestive malignancies (laryngeal carcinoma and carcinoma of tongue) constituted $3.8 \%$ of patients.

Table 1. Aetiology of secondary otalgia.

\begin{tabular}{lcccc}
\hline \multicolumn{1}{c}{$\begin{array}{c}\text { Aetiology of } \\
\text { referred otalgia }\end{array}$} & $\begin{array}{c}\text { No. } \\
(\%)\end{array}$ & $\begin{array}{c}\text { Mean } \\
\text { age } \\
\text { (years) }\end{array}$ & $\begin{array}{c}\text { Males } \\
(\%)\end{array}$ & $\begin{array}{c}\text { Females } \\
(\%)\end{array}$ \\
\hline $\begin{array}{l}\text { Temporomandibular } \\
\text { joint dysfunction }\end{array}$ & $\begin{array}{c}30 \\
(37.9 \%)\end{array}$ & 34.7 & 12 & 18 \\
\hline Pharyngitis & $\begin{array}{c}19 \\
(24 \%)\end{array}$ & 29.1 & 12 & 7 \\
\hline Dental pain & $\begin{array}{c}14 \\
(17.7 \%)\end{array}$ & 26.2 & 3 & 11 \\
\hline $\begin{array}{l}\text { Cervical } \\
\text { spondylosis and } \\
\text { myalgia }\end{array}$ & $\begin{array}{c}6 \\
(7.6 \%)\end{array}$ & 43.6 & 1 & 5 \\
\hline Gingivitis & $\begin{array}{c}2 \\
(2.5 \%)\end{array}$ & 35.5 & 2 & 0 \\
\hline $\begin{array}{l}\text { Laryngeal } \\
\text { carcinoma }\end{array}$ & $\begin{array}{c}2.5 \%) \\
1\end{array}$ & 70.5 & 2 & 0 \\
\hline $\begin{array}{l}\text { Carcinoma of } \\
\text { tongue }\end{array}$ & $\begin{array}{c}1.3 \%) \\
1\end{array}$ & 80 & 0 & 1 \\
\hline Lingual tonsillitis & $(1.3 \%)$ & 35 & 0 & 1 \\
\hline Aphthus ulceration & $\begin{array}{c}1 \\
(1.3 \%)\end{array}$ & 18 & 1 & 0 \\
\hline Facial pain & $\begin{array}{c}1 \\
(1.3 \%)\end{array}$ & 37 & 0 & 1 \\
\hline Sinusitis & $\begin{array}{c}1 \\
(1.3 \%)\end{array}$ & 6 & 1 & 0 \\
\hline Follicular tonsillitis & $\begin{array}{c}1 \\
(1.3 \%)\end{array}$ & 25 & 0 & 1 \\
\hline Total & $\begin{array}{c}79 \\
(100 \%)\end{array}$ & 33.3 & 34 & 45 \\
\hline
\end{tabular}

\section{DISCUSSION}

The average age of our patients was 33.3 years with a male:female ratio of $1: 1.3$. The prevalence of secondary otalgia increased with age and thereafter decreased in old age group. Similarly, Kuttila SJ et af reported same age distribution and that women complained from otalgia almost twice as often as did men. Moreover, Jaber JJ et al stated that the majority of their patients being of Caucasian origin and of female gender.

Our study revealed that temporomandibular joint dysfunction was the main cause of secondary otalgia $(37.9 \%)$ with a mean age of 34.7 years and females dominated over males in almost all diseases apart from pharyngitis.

Temporomandibular joint dysfunction may be related to common situations such as poorly fitting dentures, malocclusion, or nocturnal bruxism. ${ }^{1}$ Furthermore, Peroz $1 .{ }^{8}$ concluded that otalgia has to be interpreted as a possible symptom of craniomandibular disorders. Chen RC et al cited that otalgia is listed as chief complaint by $70 \%$ $78 \%$ of patients with temporomandibular joint disorders. Temporomandibular joint disorders have a 2-9 times higher prevalence in women than men and occur in both sexes between 40 and 70 years of age. Moreover, Kuttila $S J$ et $a^{\hat{f}}$ stated that all authors agree that sufferers of secondary otalgia of temporomandibular joint dysfunction are more likely to be females, with statistically elevated levels of physical comorbidity and psychological stress.

On the contrary, Flood $\mathrm{LM}^{9}$ believed that dental causes are the main causes of secondary otalgia. We can explain this variation by the fact that temporomandibular joint disorders and dental pain cause referred ear pain via the trigeminal nerve and both conditions can be presented simultaneously. Indeed, dental problems can lead to temporomandibular joint disorders.

Pharyngitis was the second cause of otalgia in our series with a male predominance and mean age of 29.1 years. John et $a l^{\beta}$ reported that tonsillitis and pharyngitis are very common causes of earache in children, less commonly laryngitis, laryngeal tumours, oesophagitis and even angina pectoris may manifest as otalgia. Similarly, Abdullah $\mathrm{V}$ et al. ${ }^{1}$ Stated that common infections often have referred otalgia as a major symptom, particularly tonsillitis, quinsy, or post-tonsillectomy 
infection via the glossopharyngeal nerve, and mumps parotitis by stretching the sensitive parotid fascia via the trigeminal nerve.

Cervical spondylosis and myalgia constituted $7.6 \%$ of causes of secondary otalgia in our patients. Jaber $\mathrm{JJ}$ et $\mathrm{al}^{7}$ in studying cervical spine causes for referred otalgia believed that cervical spine degenerative diseases in the elderly will begin to emerge as a major aetiological source for referred ear pain as elderly citizens aged 65 and over constitute over $13 \%$ of the United States population.

In our study we labeled the patient to have secondary otalgia after excluding any primary cause. Dentist and rheumatologist consultation was obtained accordingly to confirm the diagnosis.

Kuttila SJ et af suggested that in patients with otalgia, it is important initially to rule out infectious otologic and nasopharyngeal diseases that may cause aural pain. Thereafter, the patient should be referred to a stomatognathically experienced dentist to rule out stomatognathic causes of otalgia. If there is doubt after dental clinical examination, infiltration of local anaesthetic around a suspected tooth may produce temporary relief and thus diagnostic confirmation. If no stomatognathic cause of otalgia can be found, the next step is to explore the frequency of stress symptoms, bruxism, and recurrent neck pain. ${ }^{6,8}$

Rarely, secondary otalgia may be the sole presenting symptom of some diseases. Vedasalam et $\mathrm{al}^{10}$ described a peculiar 74 years old woman with internal laryngocele who presented with severe right ear pain associated with bleeding and vertigo of 2 months duration. Moreover, Amirhaeri $S$, Spencer D and Sheikh $M$ et al ${ }^{11,12}$ each presented two patients with sudden ear pain as the sole presentation of cardiac ischaemia. The underlying pathophysiology of the referred otalgia in these patients can be explained by the autonomic dysfunction of the auricular branch of the vagus nerve.

Although these are very rare presentations as they are not shown in our series, the importance of recognizing them is vital, as outcomes may be worsened and appropriate therapy may be delayed or misdirected.

Despite the low frequency of malignant upper aerodigestive tract tumours in our study as only 3 patient $(3.8 \%)$ suffering from carcinoma of larynx and tongue presented with secondary otalgia, a well-known strong association between cancer and otalgia exists and the results of missed diagnosis can be devastating. ${ }^{3}$ Visvanathan V. and Kelly $G .{ }^{13}$ believed that the main concern in a patient with referred otalgia is overlooking a malignant lesion in the upper aerodigestive tract or base of skull/infratemporal fossae. Moreover, Leonetti JP et $\mathrm{al}^{14}$ reported that otalgia could be an isolated symptom of malignant infratemporal tumors. Adenoid cystic carcinoma was the most commonly seen tumor in their patients.

From these findings we recommend to consider laryngeal and pharyngeal cancer as a cause of earache in patients with normal ear findings.

\section{CONCLUSION}

Temporomandibular joint dysfunction, pharyngitis, dental problems and cervical nerve root pain were the commonest causes of secondary otalgia. Moreover, upper aerodigestive tract malignancies should be considered in the differential diagnosis.

\section{REFERENCES}

1. Abdullah V, Bleach $\mathrm{N}$, Andrew van hasselt $\mathrm{C}$. Referred Otalgia. Hong Kong Practitioner 1993;15(4); 2559-2561.

2. Chen RC, Khorsandi AS, Shatzkes DR, Holliday RA. The Radiology of Referred Otalgia. Am J Neuroradiol 2009; 30(11):1817-23. [cited Oct. 2012]. Available from: URL:http://www.ivsl.org.

3. John C Li, Brunk J. Otalgia. Emedicine. last updated; Aug 26, 2008. [cited Oct. 2012]. Available from: URL: http://www.ivsl.org.

4. Reiß M, Reiß G. Differential Diagnosis of Otalgia. Schmerz 1999;13:392-397.

5. Wong DL, Hockenberry-Eaton M, Wilson D, Winklestein ML, Schwartz P. Wong's Essential of Pediatric Nursing. $6^{\text {th }}$ ed. St. Louis; 2001. p. 1301.

6. Kuttila SJ, Kuttila MH, Niemi PM, Le Bell YB, Alanen PJ, Suonpaa JT. Secondary Otalgia in an Adult Population. Arch Otolaryngol Head Neck Surg. 2001; 127:401-405.

7. Jaber JJ, Leonetti JP, Lawrason AE, Feustel PJ, Maywood IL and Albany NY. Cervical Spine Causes for Referred Otalgia. Otolaryngology-Head and Neck Surgery 2008;138(4):479-485.

8. Peroz I. Otalgia and Tinnitus in Patients with Craniomandibular Disorders. HNO 2001;49:713-718.

9. Flood LM. Otalgia. In: Gleeson M. editors. ScootBrown's Otorhinolaryngolgy Head and Neck Surgery. Vol. 3. $7^{\text {th }}$ edition. Hodder Arnold; 2008.p.3526-3536.

10. Vedasalam S, Sipaul F, Porter G. Internal Laryngocoele and Referred Otalgia. BMJ 2010 Nov, 26. [cited Oct. 2012]. Available from: URL: http://www.ivsl. org.

11. Amirhaeri $S$ and Spencer D. Myocardial Infarction with Unusual Presentation of Otalgia: A Case Report. Int J Emerg Med 2010;3:459-460. 
12. Sheikh M, Adlakha S, Chahal M, Bruhl S, Pandya U, Saeed B. Cardiac Otalgia: Acute Coronary Syndrome Masquerading as Bilateral Ear Pain. Cardiol J 2010; 17(6):623-4.

13. Visvanathan V, Kelly G. 12 Minute Consultation: An Evidence-Based Management of Referred Otalgia. Clin Otolaryngol 2010;35(5):409.
14. Leonetti JP, Li J, Smith PG. Otalgia: An Isolated Symptom of Malignant Infratemporal Tumors. The American Journal of Otology 1998;19(4). [cited Oct. 2012]. Available from: URL:http://www.ivsl.org. 